Journal of Jungian Scholarly Studies

Vol. 9, No. 4, 2014

\title{
So You Want to be a Change Agent
}

\author{
Susan Wyatt, Ph.D. \\ Antioch University Los Angeles
}

\begin{abstract}
This paper analyzes a range of theories of change agency for the purpose of exploring possible ways for individuals to practice social change that are inspired by Jungian thought. The methodology for this paper is a narration of various theories of social and organizational change. The study uses variations of the story of the Rainmaker, told by C. G. Jung, to explore the connection between individual and social change. The conclusion considers the contribution that Jungian theory can make to the resolution of the tensions that are inevitably engendered by the thoughtful facilitation of social change.
\end{abstract}

\section{Individual Change and Social Change}

Many Jungian scholars share a concern for social issues. The challenge that many of them experience when considering such issues from a psychological perspective is figuring out how their concerns can be translated into action. ${ }^{1}$ The question of translating concern into action has resonated for me for some time, especially during the time that I was working on a degree in organization development, a field whose practitioners refer to themselves as "change agents." The exploration of theories of change agency that I undertook in an attempt to provide useful suggestions for Jungian scholars looking for a way to practice social change agency is the basis for this narrative.

We can get an idea of C. G. Jung's view of social change from the story of the Rainmaker that he used to illustrate the point that the place to seek solutions to social issues is in oneself (Jung, 1955-56, pp. 419-420). To summarize the story:

There was a great drought and when the situation looked to be catastrophic, the people called in the Rainmaker. The only thing he asked for was to be left alone in a little house where he locked himself in for three days. On the fourth day the clouds gathered into a great storm. When the people asked him how he brought the rain, the Rainmaker replied: "Oh, I am not responsible. I come from another country where things are in order. Here they are out of order, and I was not in Tao because I was in a disordered country. So I had to wait three days until I was back in Tao, and then naturally the rains came." 


\section{Journal of Jungian Scholarly Studies 2}

Jungian theory, with its emphasis on the participation of individuals in the evolution of consciousness, is implicitly a theory of social change (Hart, 1997). However, since Jung held that the individual is the carrier of consciousness, any theory of social change based on classical Jungian thought must begin with the individual. "Jung emphasized that every change must begin with the individual himself and not with trying to improve other people; the latter he regarded as a display of the power complex" (von Franz, 2007, p. x). However, individuation is a social process because the individual becomes aware of the meaningfulness and purpose of the human journey, consciously and creatively related to the collective (Hart).

According to Renos Papadopoulos (1997b), individuation can be seen as taking place in three stages. We begin in a state of undifferentiated nature and move into a state of differentiated ego through a process of separation that establishes a collection of personal identities connecting with collective identities. The paradox is that as the ego becomes more differentiated, we become more enmeshed in collective structures. As we become more conscious, we become aware of our separation and develop a longing to return to oneness with nature. The only solution is individuation, which puts ego and nature back together again in the context of the collective.

Brazilian educator Paulo Freire has been one of the most powerful influences on post-colonial theories of change agency. In the Cambridge Companion to Jung, Lawrence Alschuler (1997) focused on individuation in relation to Freire's process of conscientization, the political development of the person. Conscientization also takes place in three stages (Freire, 1972). In the first, magical consciousness, people name the problems of their existence but feel no power or responsibility to change them. In the second, naïve consciousness, a person identifies problems in terms of individual oppressors. Individuals reflect on the causes of their problems in a personal context and may come to internalize the oppressor's ideology or may attempt to remove the oppressor. In the third stage of conscientization, critical consciousness, individuals can identity problems in the context of the community rather than just as personal problems. They are able to take collaborative action to achieve both self-actualization and transformation of the system. The goal of individuation is wholeness, while the goal of conscientization is humanization. Individuation supports conscientization in moving towards these compatible goals (Alschuler). The critical question, whether talking about individuation or conscientization is how individual change is connected to social change. In both cases, social change is impossible without individuals changing, and individuals cannot change without coming into a different relationship to the collective.

This question is both mysterious and fascinating and I have attempted to understand it through a series of metaphors. Individuation has been compared to weaving a tapestry (Moreau, 1997). The process of individuation is a process of 


\section{Wyatt}

weaving oneself as a unique individual into the collective. The strength of the tapestry depends on the integrity of the individual threads and the care with which they are woven into the pattern of the tapestry. Individuation is also frequently compared to a dance (Moreau). Rhythm is a fundamental property of the structure of the universe, all matter and energy pulsating in continual rhythm (von Franz, 1974). All living beings follow the rhythms of biological clocks. Our own brains too have a rhythmic organization. Social change can be created (temporarily) simply by beating a drum in a repeated 1-2 rhythm. It takes only a short time before the heartbeat of every person in the room is synchronized to the beat of the drum. Individuation is an experience of the underlying rhythm of the cosmic dance, participating in the dance of life with the equilibrium of psychic wholeness, moving through ordinary activities in a natural, integrated, and spontaneous way. Social change, in this metaphor, occurs through the process of entrainment. Even if individuals can dance only to a faint echo of the cosmic rhythm, they draw others to engage simply through the power of the dance.

In thinking about the connection between individual and social change it occurred to me to ask what the Rainmaker was doing during the three days in his tent. Taoist theory would lead to a surmise that he was doing qigong, or "energy work." Such work might have involved calming his breath and clarifying his inner vision to achieve "an awareness of an underlying oneness through which we are connected to everything in the universe" (Bolen, 1979, p. 23). I like to imagine that he was moving his body in the motions of the qigong forms. These are based on the principle of circulating energy drawn up from the earth and pulled down from heaven and, thus, becoming a partner with heaven and earth in the cosmic balance. In fact, Roger Jahnke has proposed performing qigong as a method of social change agency. "With the widespread use of Qigong and Tai Chi, the purposeful evolution of individuals and groups is neither impossible nor costly" (Jahnke, 2002, p. 278).

\section{Theories of Social Change}

Although Jungian theory clearly connects changing an individual to social change, the dominant contemporary paradigm seems to involve the change agent in direct intervention in social systems. I have often wondered what happened to the country where the drought occurred in Jung's story after the Rainmaker departed; and have imagined a number of ways that the story might continue.

\section{Return to Tao}

Although the Rainmaker had to return to his own country, he had aligned the energy in such balance that the rains fell regularly for an entire season. However, the next year the land was again plagued by drought. The people remembered his 


\section{Journal of Jungian Scholarly Studies 4}

explanation that the rain did not fall because the country was in disorder. "If we want it to rain, the entire country must be brought into Tao," said the change agents.

Most contemporary theories of change agency aim at a transition from the present to some desired future state. However, social change has often driven toward a return to a former state to take a different path. The basic assumption is that something is broken that needs to be fixed. Although the theories are seldom based on the assumption of fixing a broken system, I have found it remarkably easy to be captured by it. Faced with the overwhelming scale of suffering in the world, we can easily get "caught up by the irresistible urge to do something" (Papadopoulos, 1997, p. 10). We start thinking that everything would be all better if we could just get rid of hierarchy, patriarchy, bureaucracy, Wall Street, exploitation, and pollution or if we could institute participation, sustainability, diversity, ecology and so on. After all, does it not seem a reasonable conclusion to the story to bring the country into Tao? However, such approaches lead inevitably to paradox and potentially to violence. What is going to be done with people who do not want to be in Tao?

For me the paradox of the return for a better start was difficult to work through. Although dissatisfied with the world and remaining committed to changing it, I also had not only to accept but to embrace the condition of the world as it is. If it is in crisis, then crisis is natural and should be faced not just with anguish but, with a full range of human emotions such as curiosity, humor, and gratitude. "The human struggle must abandon the fascinating attractions of archetypal possession in order to return to more human states of confusion, complexity, and suffering" (Papadopoulos, 1997, p. 25).

\section{Adaptation: Change or Die}

Although the Rainmaker was able to bring the rain, as soon as the year turned to the next dry season, the country again found itself in a drought. "Our climate has changed," said the change agents, "and we must adapt to living with less water. We will bring in technical experts who will show us how to plant low-moisture crops and design irrigation systems."

The basic idea of the approach of the return for a better start is to fix things and then stabilize them once we get them right. As in Plato's Republic, once the perfect social organization is established nothing need ever again be changed. Heraclitus, on the other hand, held that all things are in constant flux, but he also believed that change is governed by fixed laws (Hadas, 1950). The Gaia hypothesis is an expression of a similar idea in scientific language. "The Gaian idea is that life makes and remakes its own environment to a great extent" (Margulis and Sagan, 1997, p. 146). Taoist theory also sees the universe in a state of continuous change. 


\section{Wyatt}

The I Ching (Book of Changes) "attempts to describe the Universe and its myriad changes and to reduce them to an ordered and comprehensible system" (de Bary, 1960 , p. 192). Social change is conceived as living in harmony with such mutability.

Contemporary theories of change agency often see the reason for change not just as harmony or even effectiveness but as survival. Such adaptive theories are important because they focus on the boundaries and connections between humans and our social and physical environments. They see social change as not merely a quest to achieve human goals, but also as a search for our rightful place in relation to the Earth and the Cosmos.

However, individuals have sometimes been ambivalent towards adaptation and are often resistant to change. Although reality may be in a state of continuous change, most technological, economic, political, and cultural change is created by humans. In the endless paradox of creating change to adapt to the change we have created, we risk losing our connection with nature. Of all the tensions involved in a study of social change, I find none more troubling than the apparent polarity between human needs and the needs of the environment. I say "apparent" because humans are not really separate from nature. However, meaningful social action must constantly encompass this tension between human needs and environmental issues.

\section{Values-Based Change: Social Construction}

Although the Rainmaker was able to bring the rain, the experience of the drought had made the community aware that they did not have any way of coping with these disasters that occurred every few years. "We know we will have droughts in the future," said the change agents, "and we must find a way to distribute the water more fairly so that no one will suffer.'

If reality is constantly changing then the best that social change can do is to adapt to it. However, social change can be a means of constructing reality according to certain shared values. Johnson (1982), writing on revolutionary change, offers a general methodology for these approaches in the synchronization of the structure of division of labor with the value pattern of a society (whatever those values might be). Social change since the Renaissance, for example, has often been based on humanist values such as tolerance, skepticism, and respect for complexity and diversity (Toulmin, 1990). Contemporary theories of social change often include values such as social justice or making a profit (organization development includes both). To me the most interesting models for change are those that value action based on knowledge. Examples of such knowledge-based theories include action research, active adaptation, participatory research, appreciative inquiry, and mindful inquiry. 


\section{Journal of Jungian Scholarly Studies 6}

\section{Action Research}

Action research was developed by Lewin and his colleagues, sociologists who wanted to find ways to apply their work in organizational settings. The basic elements of the method are diagnosis, intervention, and evaluation. Action research aims at simultaneously intervening in and generating knowledge about social systems. An idea often attributed to Lewin is that the best way to understand a system is to try to change it (Schein, 2012). His work has been very influential in almost all $20^{\text {th }}$ century theories of social or organizational change. Most of these theories seem quite sanguine about the ethics of trying to understand a system by intervening in it.

\section{Participatory Research}

Participatory research, based on the ideas of Freire, is aimed at material wellbeing and socio-political entitlement without suppression of "traditional ways" by industrial culture (Park, 1993, p.18). Ordinary people who want to bring about change in their society are the change agents - the ones who both generate and use the required knowledge. Participatory research is based on the assumption that the "people's wisdom" is still accessible in the collective memory to provide a communal unity, especially in less-developed parts of the world (Park, p.19).

\section{Mindful Inquiry}

Mindful inquiry is another knowledge-based approach to social change that explicitly involves research (Bentz \& Shapiro, 1998). It takes the goal from critical social theory of "expanding the scope of freedom, justice, and happiness" (p. 146) and, from Buddhism, of "the elimination or diminution of suffering" (p. 6). The focus of this approach to social change is on research that synthesizes aspects of critical social science, phenomenology, hermeneutics, and Buddhism that is linked to some project aimed at the above goals. In some respects, mindful inquiry is at the opposite end of the spectrum from action research. While mindful inquiry emphasizes ethical responsibility, it is not clear how this approach translates knowledge into a framework for action.

\section{Active Adaptation}

Theories of active adaptation provide approaches to change within a humanist framework. One example is the socio-ecological approach developed at the Tavistock Institute (Trist, Emery, and Murray, 1997). The key to this approach is replacing representative democracy with participative democracy, using methods such as decentralization and debureaucratization. The Tavistock authors expose the negative effects of representative democracy but do not voice any misgiving that participative democracy may have a dark side. 


\section{Wyatt}

The authors of the socio-ecological approach have described a phenomenon they call hyperturbulence, which emerges when the environmental demands finally exceed the collective adaptive capacities of members who share the environment (McCann and Selesky, 1997). In a state of hyperturbulence, population growth and technological innovation drive increasing demands of social interaction as resources become increasingly scarce. The authors argued the need for radically different social institutions to deal with the hyper-complexity in our social environments. "To raise institution building to a new level of consciousness is a primary task of the present era" (Trist, 1997, p. 560). They pointed out, however, that such solutions can only be effective if the individuals using them are faring well in managing their own complex personal environments. So active adaptation explicitly intertwines individual and social change. Trist concluded that individuals are more adaptive to turbulence than the social systems in which they are embedded. "We must, therefore, put our trust in the resilience of individuals and their capacity to change systems and invent alternatives" (Trist, p. 560).

\section{Appreciative Inquiry}

The goal of appreciative inquiry is health and vitality in a social system (Whitney, Trosten-Bloom, \& Cooperrider, 2010). Rather than taking problems as a starting point, appreciative inquiry focuses on a life-giving past to envision a preferred future. The methodology includes valuing the best of what is, envisioning what might be, dialoguing what should be, and innovating what will be. Although at first glance it is not a Jungian method, the inspiration for the approach is explicitly attributed by Cooperrider, the originator of appreciative inquiry, to a quotation from Jung (1967, p. 15).

All of the greatest and most important problems of life are fundamentally insoluble. They can never be solved, but only outgrown. Some higher wider interest appeared on the horizon and through this broadening of outlook the insoluble problem lost its urgency. It was not solved logically in its own terms but faded when confronted with a new and stronger life urge.

With its emphasis on positive discourse, appreciative inquiry can be seen from a Jungian perspective as turning away from the shadow. This is often what has happened in the hands of practitioners who rigorously follow standardized models. However, quite the opposite can be seen when appreciative inquiry has been implemented without preconceived judgments of what constitutes "positive discourse." When members are asked what gives an organization or community health and vitality, they quite often find these qualities in the very capacities that have been suppressed and devalued. "Shining the light on people's strengths created an awareness of how many people in the organization were not affirmed for 


\section{Journal of Jungian Scholarly Studies 8}

what they were contributing to the organization's goals. They expressed a deep sense that there were many unsung contributors who had made the company the success it is today" (Fitzgerald, Oliver, \& Hoxsey, 2010).

\section{Paralyzed by Paradox}

While change agents have had some success in implementing each of these values-based models, the intentions of the theories are not necessarily translated into outcomes. The results of many social change efforts have been constantly increasing demands by organizations on individual's time and energy. While I have found inspiration in knowledge-based change models, whenever I examine their assumptions in any depth, I become mired in paradox. How can we change a system without intervening in it; but how can we ethically intervene in a system that we do not understand? In fact, paradox seems to be embedded in every model of change agency - whether based on problem-solving, adaptation, values, or creating entirely new patterns.

Handy has pointed out that we live in "the age of paradox." The paradox of justice, for example, is that being treated fairly can be interpreted as being given what we deserve or as being given what we need. Is it fair, for example, for the people in the story to give the most water to the cities where the majority of the population lives, or should it be diverted to the farmers who grow food for everyone? And who should make such decisions? Julia Kristeva has highlighted another dilemma - the difficulty of dismantling the centralization of power that leads to injustice without taking over that power oneself (Oliver, 1993).

Examining the models through the lens of dynamical systems theory reveals yet another paradox. Social change can take place on a continuum ranging from adaptive modification in a system to radical transformation of a system (Sztompka, 1993). If the intention is transformation, then it does not make sense to engage in adaptive change because it merely brings a system into a new equilibrium and allows it to avoid fundamental change. On the other hand, radical transformation cannot be planned because the state of a system after such a bifurcation cannot be predicted or controlled. "The final state of a system cannot be predicted with certainty if there is any error (no matter how small) in the measurement of initial conditions. It isn't even possible to make a rough guess about the system's ultimate fate" (Peterson, 1998).

Few planned change efforts produce lasting social change because they do not is that they do not take into account the power of the unconscious. Theories of organization development and social change include dimensions such as structures, functions, boundaries, and environments (Sztompka,1993) but seldom refer to images, metaphors, and myths. Synthesizing elements of Jungian theory offers an approach that overcomes this limitation. Several authors have made attempts at a Jungian social change theory based on extending the Jungian model of the 


\section{Wyatt}

individual to the collective psyche. In Mapping the Organizational Psyche (2003), for example, Corlett and Pearson derived an organizational analogue of the Jungian model of the psyche. I recognized from the conclusions of dynamical systems theory about the dependency of the outcome of change efforts upon the initial conditions that a theory of planned radical change was not a possible outcome. However, my efforts at a synthesis really came up against a wall when I came upon this quotation: "Nothing good can come into the world without at once producing a corresponding evil" (Jung, 1964, p. 77).

At this point I was so deeply mired in paradox that I considered giving up on theory entirely and went back to reread the Bhagavad Gita, which instructs that engagement in action should be an act of devotion and service. Values should be the ground of social action rather than the goal. So the question I might ask as a Jungian scholar is not how I can resolve social issues or achieve outcomes such as freedom or justice, but how to serve the process of evolving consciousness. "We know we want to get somewhere, but we have to relinquish control over the place we might end up in, and even consider the possibility of arriving nowhere at all" (Beck, 2012, p. 92).

Although the Bhagavad Gita provides some of the best advice I have been able to find for a change agent, it still left me in the grip of paradox. "Be intent on action, not on the fruits of action" seems to be in direct opposition to the guiding principle of "do no harm." And it is in dealing with tensions such as these that Jungian theory can be of immense value to any change agent. Whatever paradoxes one faces, they can be contained within the form of a mandala. I have always been drawn to the Celtic knot version of the mandala and conceiving of change agency in this way has allowed me to envision weaving together many strands that might be seen as opposites. My own mandala is always a work in progress. The form and content of the mandala is likely to be unique for any individual trying to come to terms with the paradoxes involved in the practice of change agency. "Each will ultimately write their own book for facilitating change" (Corbett \& Pearson, 2003, p. 106).

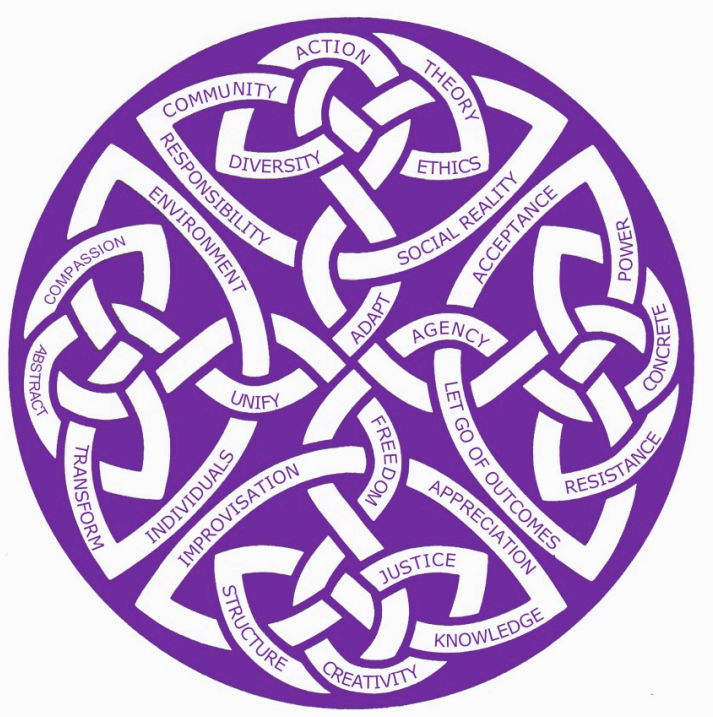




\section{Journal of Jungian Scholarly Studies 10}

\section{The Practice of Social Change}

Although my explorations did not result in a synthesis, they did discover a convergence. I found that many fields ranging from sociology to management have reached the conclusion that change agency requires a narrative approach. Postmodern theorists in particular have emphasized the small narrative: "a common story that promotes a bond between individuals in their daily life" (Rosenau, 1992, p. 85). Sztompka (1993) has found that narrative offers possibilities for mediating the tensions in agency in sociology. In organization development, Schein (2012) and Polkinghorne (1988) have both suggested rewriting stories as a change methodology. The change agent can assist "in the emergence of a new narrative that is more integrative and that addresses the tensions of the organization better than the old one" (Polkinghorne, p. 123).

Jungian practice is also based on a narrative approach. "Most psychotherapeutic systems, in effect, offer various forms of re-storying experiences so that they acquire a wider validity" (Papadopoulos, 1997, p. 21). The psychoanalytic approach has often been aimed at helping people to adapt their story within the narratives of their society. However, when the dominant myths of a society no longer give any meaning to human experience, it makes no sense to help people adapt to soulless myths. Instead, the attention of the change agent must shift to adapting social narratives to the need of individuals for meaning. The approach suggested by Papadopoulos is facilitating the construction of narratives that take into account the oppositionalities that are repressed in the collective shadow. It is the archetypes that provide the underlying unity that makes collective narrative and metanarrative possible (Gray, 1996). The system is brought back into balance by the activation of archetypes in the collective unconscious that appear as powerful images and symbols. In a culture that has split itself to become hyperrational, for example, they intrude to insert irrationality into our lives (Papadopoulos, 1998). A coherent narrative derives meaning from the whole of our experience and accounts for as many dimensions, including shadow aspects, as possible. The story gains coherence from metaphor, symbol, image, and art.

\section{Conclusion}

All change agents must discover and create a personal story for their practice. In my story, engagement in social change tries to balance action and knowledge. It is grounded in service, even when the intention is to bring about some desired outcome. It is particularly important to me to find ways to practice social change in a way that brings humans into harmony with their environment. It is also important to help individuals resist exploitation by organizations.

Although I sometimes become involved in interventions, these are usually projects that involve the use of narrative. One example is an organization that 


\section{Wyatt}

provides storybooks to be used in drug prevention programs for children. I am particularly fascinated by exploring organizations to help them become aware of how their underlying narratives influence their behavior. One engineering organization, for example, was unable to make sound business decisions because their most valued narrative was that of technical heroism.

I also bring narrative into my research and teaching practice. For example, instead of using anonymous surveys for evaluation, I ask participants for a short narrative that lends coherence to their experience of the process. I have found that, for me, the best way to deal with the excruciating paradoxes of change agency is through creating, collecting, and telling stories.

\section{References}

Beck G. (2012). Occupying uncertainty and the OWS movement. In J. Shapiro and R. Partridge (Eds.). Occupy Psyche: Jungian and archetypal perspectives on a movement (pp 89.-112). Techné and Poiésis.

Bentz, V. M., \& Shapiro, J. J. (1998). Mindful inquiry in social research. Thousand Oaks, CA: Sage.

Bolen, J. S. (1979). The Tao of psychology. San Francisco: Harper.

Corlett, J. G. \& Pearson, C. S. (2003). Mapping the organizational psyche: A Jungian theory of organizational dynamics and change. Gainesville, FL: Center for Applications of Psychological Type.

De Bary, W. T. (1960). Sources of Chinese tradition. New York: Columbia University Press.

Fitzgerald, S. P., Oliver, C., \& Hoxsey, J. C. (2010). Appreciative inquiry as shadow process. Journal of Management Inquiry 19(3), 220-233.

Freire, P. (1972). Pedagogy of the oppressed. New York: Seabury Press.

Gray, R. M. (1996). Archetypal explorations: An integrative approach to human behavior. London: Routledge.

Hadas, M. (1950). A history of Greek literature. New York: Columbia University Press.

Handy, C. (1994). The age of paradox. Boston: Harvard Business School.

Hart, D. L. (2008). The classical Jungian school. In P. Young-Eisendrath \& T. Dawson (Eds.), The Cambridge companion to Jung ( $2^{\text {nd }}$ ed) (pp. 95-106). Cambridge: Cambridge Univeristy Press.

Jahnke, R. (2002). The healing promise of qi. New York: McGraw Hill.

Johnson, C. (1982). Revolutionary change. Palo Alto, CA: Stanford University.

Jung C. G. (1955-56). Mysterium conjunctionis. Sir Herbert Read et al. (Eds.) (R. F. C. Hull, Trans.). The collected works of C. G. Jung (Vol. 14). Princeton, NJ: Princeton University Press.

Jung, C. G. (1964). The spiritual problem of modern man. In H. Read, M. Fordham, G. Adler, \& W. McGuire (Eds.). (R. F. C. Hull, Trans.). The collected works of C. G. Jung (Vol. 10, pp. 7496). Princeton, NJ: Princeton University Press.

Jung C. G. (1968). Commentary on "The Secret of the Golden Flower. In H. Read, M. Fordham, G. Adler, \& W. McGuire (Eds.). (R. F. C. Hull, Trans.). The collected works of C. G. Jung (Vol. 13). Princeton, NJ: Princeton University Press. 


\section{Journal of Jungian Scholarly Studies 12}

Margulis, L., \& Sagan, D. (1997). Slanted truths: Essays on Gaia, symbiosis, and evolution. New York, NY: Springer-Verlag.

McCann, J., \& Selsky, J. (1997). Hyperturbulence and the emergence of type V environments. In F. E. Eric Trist, Hugh Murray (Eds.), The social engagement of social science: A Tavistock anthology (Vol. 3: The socio-ecological perspective, pp. 147-169). Philadelphia, PA: University of Pennsylvania Press.

Moreau, C. (1997). Women's psychological stages. Lecture presented at Zurich, Switzerland.

Oliver, K. (1993). Reading Kristeva: Unraveling the double-bind. Indianapolis: Indiana University Press.

Papadopoulos, R. (1997a). Individual identity and collective narratives of conflict. Harvest, 43(2), 7 26.

Papadopoulos, R. (1997b). Jungian concept of the life cycle. Lecture presented at Wildhaus, Switzerland.

Papadopoulos, R. (1998). Trauma: Transitions to healing. Lecture presented at Wildhaus, Switzerland.

Park, P. (1993). What is participatory research? A theoretical and methodological perspective. In P. Park, M. Brydon-Miller, B. Hall, \& T. Jackson (Eds.), Voices of change: Participatory research in the United States and Canada (pp. 1-20). Toronto: The Ontario Institute for Studies in Education.

Peterson, I. (1998). The jungles of randomness: A mathematical safari. New York: John Wiley.

Polkinghorne, D. E. (1988). Narrative knowing and the human sciences. Albany, NY: State University of New York.

Rosenau, P. M. (1992). Post-modernism and the social sciences: Insights, inroads, and intrusions. Princeton, NJ: Princeton University Press.

Schein, E. H. (2012). Organizational culture and leadership. Jossey-Bass: San Francisco.

Sztompka, P. (1993). The sociology of social change. Oxford: Blackwell.

Toulmin, S. (1990). Cosmopolis: The hidden agenda of modernity. Chicago, IL: University of Chicago Press.

Trist, E. (1997). Quality of working life and community development. In F. Emery, E. Trist, \& H. Murray (Eds.), The social engagement of social science: A Tavistock anthology (Vol. 3: The socio-ecological perspective, pp. 147-169). Philadelphia, PA: University of Pennsylvania Press.

Trist, E., Emery, F., \& Murray, H. (Eds.). (1997). The social engagement of social science: A Tavistock anthology. (Vol. 3 The socio-ecological perspective). Philadelphia, PA: University of Pennsylvania Press.

Von Franz, M-L. (1974). Number and time: Reflections leading toward a unification of depth psychology and physics. Evanston, IL: Northwestern University Press.

Von-Franz, M-L. (2007). Foreword. In V. W. Odajnyk Jung and politics The political and social ideas of C.G. Jung (pp. ix-xiii). New York: Authors Choice Press.

Whitney, D., Trosten-Bloom, A., \& Cooperrider, D. (2010). The power of appreciative inquiry: A practical guide to positive change. San Francisco, CA: Berrett-Koehler

\section{Endnote}

${ }^{1}$ These observations are based on a number of papers presented at the 2012 Jungian Society for Scholarly Studies Conference, New Orleans, Affect and Action: Psyche in a Time of Crisis, which addressed such concerns. 